
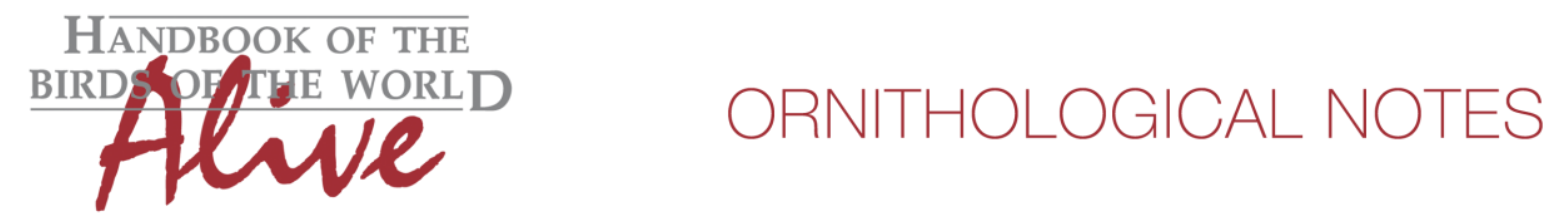

\title{
Notes on the vocalizations of Slender-footed Tyrannulet (Zimmerius gracilipes)
}

Peter Boesman

In the following we briefly analyze and compare voice of the different races of Slenderfooted Tyrannulet (Zimmerius gracilipes). We also try to quantify the extent of any vocal differences using the criteria proposed by Tobias et al. (2010), as a support for taxonomic review. We have made use of sound recordings available on-line from Xeno Canto (XC) and Macaulay Library (ML).

In previous cases of the same genus (Golden-faced Tyrannulet Z. chrysops and Paltry/Venezuelan Tyrannulet Z. vilissimus/improbus) (Boesman 2016), we have compared day-time calls rather than dawn song. It thus seems logical to do the same here.

At some point in time, comparison of dawn-song across the entire Zimmerius genus will also be necessary, to find out if there are true differences or not and whether these strengthen the vocal groups identified by differences found in day-time call, but this will require more recordings (and resources) than presently available.

The present analysis is as much an exercise in finding the exact boundaries of different vocal groups as scoring the vocal differences.

We can distinguish 4 vocal groups (Fig 1.):

group 1: North of the Amazon river in the Guianan region (western boundary in Venezuela not $100 \%$ clear): day-time call is a double note 'chu-chup' (very sharply downslurred).

group 2: South of the Amazon river (as far west as the Rio Tapajos) and S to northern Mato Grosso: day-time call is a single 'chup'.

group 3: North of the Amazon river in E Colombia, E Ecuador, NE Peru east to the Rio Negro region and into extreme SW Venezuela (gracilipes): day-time call is a mellow rising whistle 'wheet'.

group 4: South of the Amazon river in SE Peru, N Bolivia and SW Brazil (gilvus): day-time call is a short rising whistle 'whit'. 

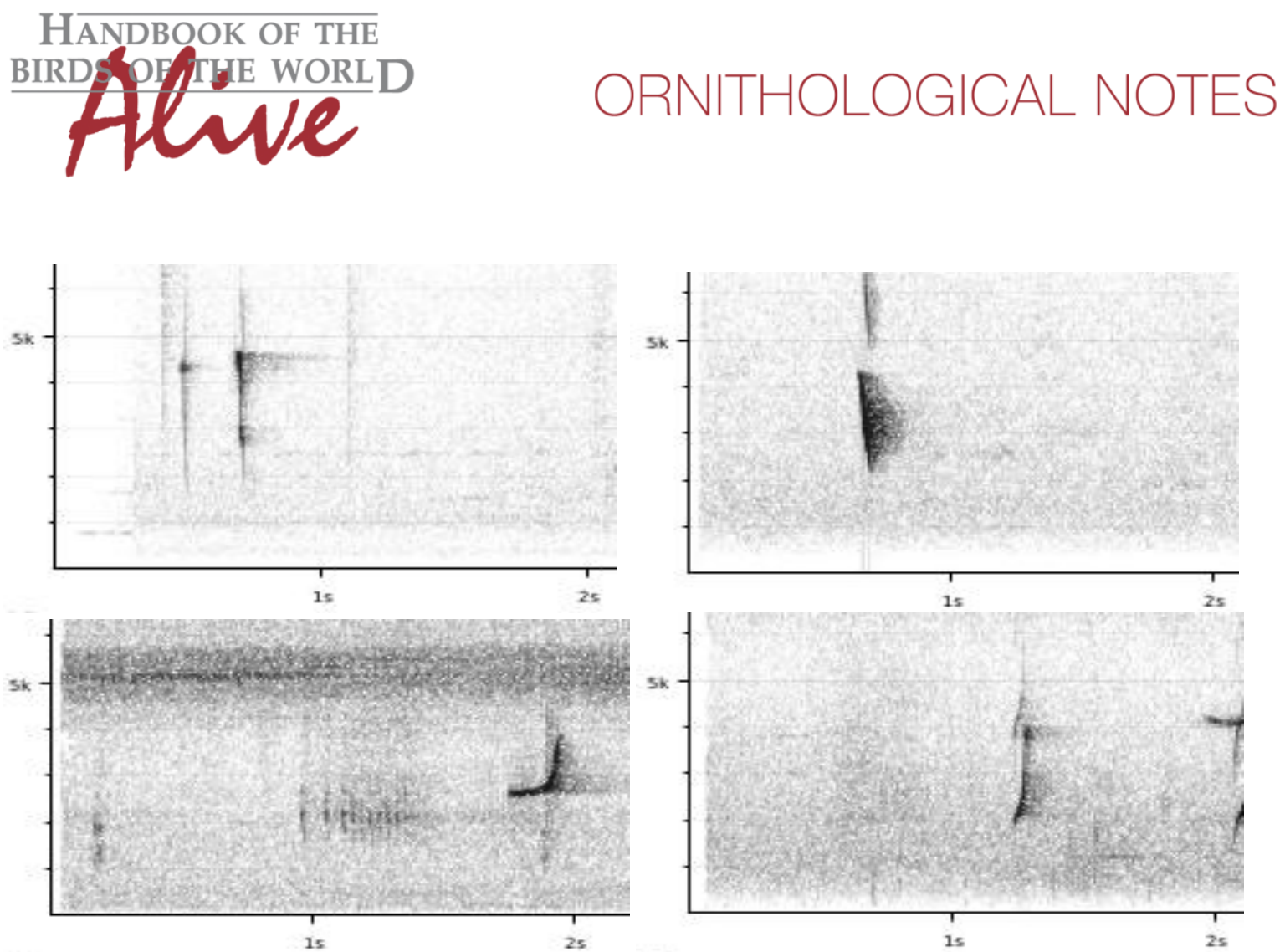

Figure 1: Typical day-time call of acer $\mathrm{N}$ of Amazon (top left), acer S of Amazon (top right), gracilipes (bottom left) and gilvus (bottom right)

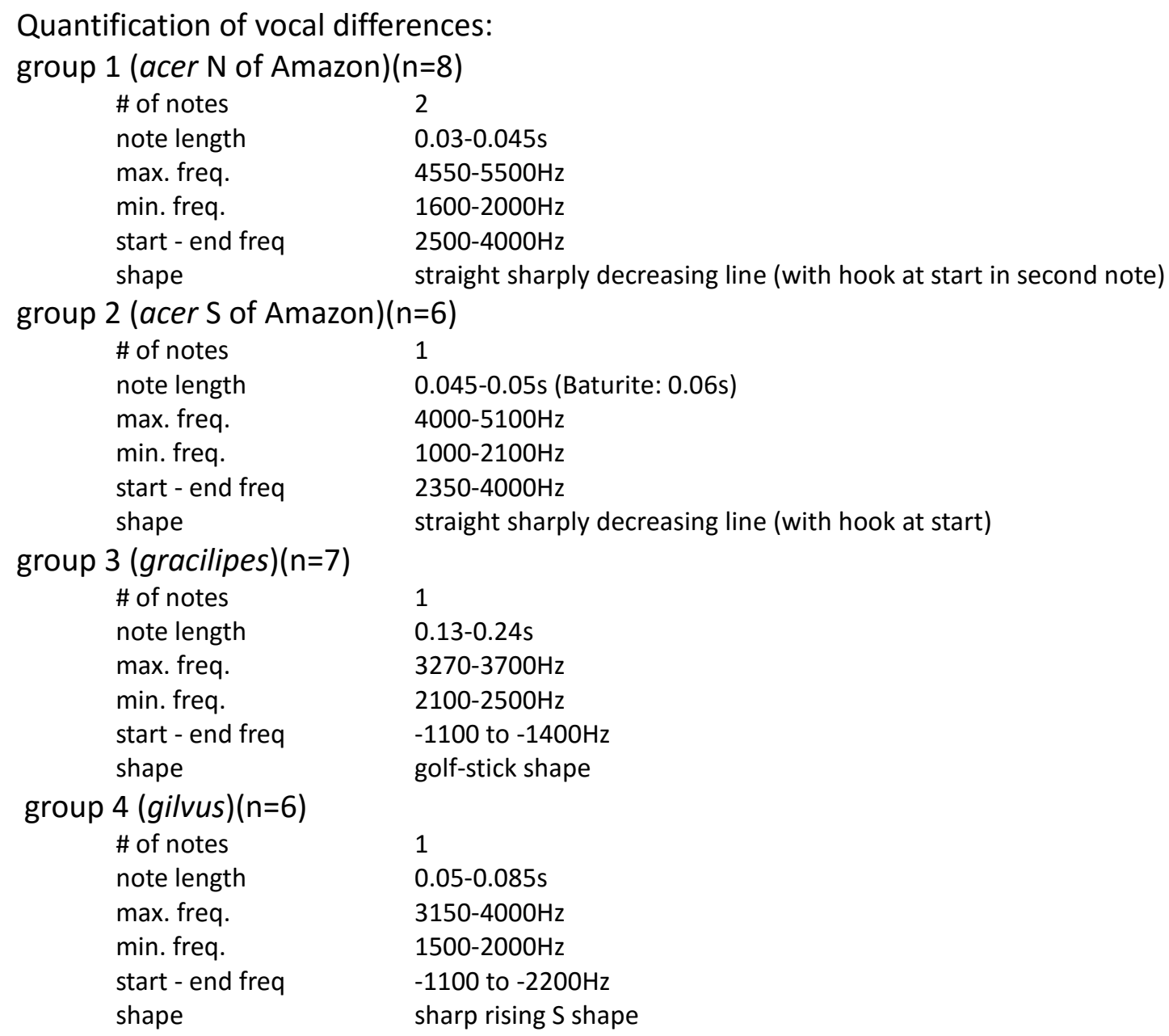



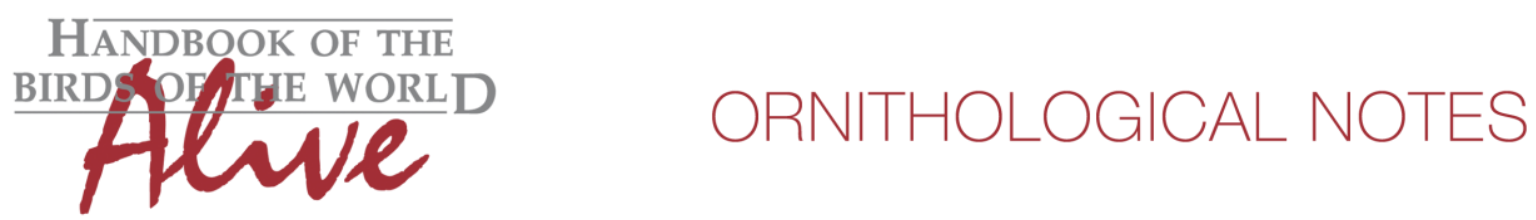

One recording from the Manaus region (from the confluence of the Rio Negro and Rio Amazon is somewhat intermediate between gracilipes/gilvus: length $0.07 \mathrm{~s}, 3750 \mathrm{~Hz}$ max, $1900 \mathrm{~Hz}$ min. $-1600 \mathrm{~Hz}$ drop, golf-stick shape) and may be an indication of hybridization (?) in the contact zone.

Based on the above measurements, we can quantify the vocal differences as follows:

$\operatorname{acer} N / S$ vs. gracilipes/gilvus: main difference is the very short note (score 1-2) decreasing in pitch (score 3 ) of the former, with higher max. frequency (score 2 ) and very different note shape (score 1-2). When applying Tobias criteria, this would result in a total vocal score of 45 .

acer $\mathrm{N}$ of the Amazon differs from acer $\mathrm{S}$ of the Amazon in emitting always 2 notes instead of one (score 3 ?), and having the shortest notes (score 1 ).

gracilipes differs from gilvus in having much longer notes (score 2) and different note shape(score 1).

This note was finalized on 28th June 2015, using sound recordings available on-line at that moment. We would like to thank in particular the many sound recordists who placed their recordings for this species on XC and ML.

\section{References}

Boesman, P. (2016). Notes on the vocalizations of Golden-faced Tyrannulet (Zimmerius chrysops). HBW Alive Ornithological Note 128. In: Handbook of the Birds of the World Alive. Lynx Edicions, Barcelona. (retrieved from http://www.hbw.com/node/932052 on 5 August 2016).

Tobias, J.A., Seddon, N., Spottiswoode, C.N., Pilgrim, J.D., Fishpool, L.D.C. \& Collar, N.J. (2010). Quantitative criteria for species delimitation. Ibis 152(4): 724-746.

\section{Recommended citation}

Boesman, P. (2016). Notes on the vocalizations of Slender-footed Tyrannulet (Zimmerius gracilipes). HBW Alive Ornithological Note 129. In: Handbook of the Birds of the World Alive. Lynx Edicions, Barcelona. (retrieved from http://www.hbw.com/node/932052 on 5 August 2016). 